\title{
Subthreshold Receptive Field Properties Distinguish Different Classes of Corticothalamic Neurons in the Somatosensory System
}

\author{
Ernest E. Kwegyir-Afful and Daniel J. Simons \\ Department of Neurobiology, University of Pittsburgh School of Medicine, Pittsburgh, Pennsylvania 15261
}

\begin{abstract}
Most corticothalamic (CT) neurons in somatosensory cortex are silent in lightly anesthetized and even awake animals, making it difficult to investigate CT function and the underlying circuitry. Here we use juxtasomal recording and stimulation techniques to probe subthreshold response properties of antidromically identified CT neurons in the rat whisker/barrel system. When neuronal firing is facilitated by depolarizing juxtasomal currents, silent neurons become responsive to whisker stimuli, permitting identification of three functional classes of CT cells: those having a short-latency excitatory response to whisker deflection, those having a long-latency response, and neurons whose firing is suppressed by whisker deflection. During sensorimotor behaviors when the CT system may be active, cells having excitatory vs inhibitory receptive fields may participate in push-pull corticothalamic circuits that, acting together, selectively enhance sensory signaling in the thalamocortical system.
\end{abstract}

Key words: corticothalamic; somatosensory; barrels; whisker; subthreshold responses; cortex

\section{Introduction}

Corticothalamic (CT) projections to first-order, specific thalamic relay nuclei from sensory and motor cortices contribute more synapses than subthalamic afferent inputs (Sherman and Koch, 1986; Liu et al., 1995; Liu and Jones, 1999). CT effects on thalamic processing are thought to be highly state dependent and dynamic, possibly varying with moment-to-moment changes in perceptual-motor behaviors (Steriade, 2001). For example, CT neurons may play an important role in sensory processing by selectively enhancing or suppressing the relay of sensory signals in a context-dependent manner (Temereanca and Simons, 2004; Lee et al., 2008). Understanding CT circuitry and function is rendered difficult by the common and surprising finding that, even in awake animals, CT sensorimotor neurons are largely silent, having little or no spontaneous activity and lacking sensorydriven, peripheral receptive fields (Landry and Dykes, 1985; Swadlow, 1994; Kelly et al., 2001; Beloozerova et al., 2005; Sirota et al., 2005) [see also vision (Tsumoto and Suda, 1980; Swadlow and Weyand, 1987)]. Available evidence suggests that "silent" CT cells possess subthreshold receptive fields (Swadlow and Hicks, 1996), but to date it has been difficult to probe them in a comprehensive manner. Similarly, many cortical neurons are silent or sparsely firing, making it difficult to assess their peripherally driven receptive fields using extracellular recording (Landry and

Received Aug. 18, 2008; revised Dec. 3, 2008; accepted Dec. 5, 2008.

This work was supported by National Institutes of Health Grant DE018015. We thank Dr. Jason Middleton for insightful comments and suggestions.

Correspondence should be addressed to Dr. Daniel J. Simons, Department of Neurobiology, University of Pittsburgh School of Medicine, 200 Lothrop Street, BST E1452, Pittsburgh, PA 15261. E-mail: cortex@pitt.edu.

DOI:10.1523/JNEUROSCI.3924-08.2009

Copyright $\odot 2009$ Society for Neuroscience $\quad$ 0270-6474/09/290964-09\$15.00/0
Dykes, 1985; Swadlow, 1989, 1990, 1991). In somatosensory cortex, for example, peripheral responsiveness of different classes of efferent neurons varies with projection target, with $\mathrm{CT}$ cells being among the least responsive (Dykes and Lamour, 1988; Metherate et al., 1988; Swadlow, 1989, 1990, 1992).

The rodent primary somatosensory cortex contains a highly specialized representation of facial whiskers in the form of morphologically identifiable neuronal clusters in layer IV called "barrels"; each barrel corresponds to a whisker on the contralateral face (Woolsey and Van der Loos, 1970). Barrels receive thalamic inputs from the ventroposterior-medial part of the ventrobasal complex (VPm); neurons there are similarly organized into "barreloids" (Van der Loos, 1976). Barreloid and barrel neurons respond preferentially and at short latency to a common whisker, referred to as the "principal" whisker (PW), and less robustly, or minimally, and at longer latency to adjacent whiskers (AW) (Simons, 1985; Armstrong-James and Fox, 1987). Thalamocortical (TC) projections into cortical barrel-related columns and VPmprojecting layer VI CT neurons are highly topographic (Land et al., 1995). The topographic nature of these projections makes antidromic identification of such neurons relatively straightforward.

Here, we employ juxtasomal recordings techniques to depolarize antidromically identified CT neurons to unmask subthreshold response properties. Findings indicate the existence of at least three different types of CT neurons that project to VPm. These cell types might be components of at least two different CT-TC circuits. Both circuits, working separately or in parallel, could enhance sensory signaling in the thalamocortical pathway.

\section{Materials and Methods}

Surgical procedures. Thirty-two adult female Sprague Dawley rats weighing 200-250 g were used in this study. Surgical procedures have been 
previously described (Simons and Carvell, 1989). Under isoflurane anesthesia (3\%), a venous catheter was inserted in the external jugular vein for subsequent administration of fentanyl and pancuronium bromide, and a tracheal cannula was inserted to maintain a clear airway. A second catheter was placed in the left femoral artery to monitor blood pressure.

The dorsal surface of the skull overlying the right ventral posterior medial thalamus (VPm) and primary somatosensory cortex were exposed. A small craniotomy, centered $3 \mathrm{~mm}$ caudal to bregma and $3 \mathrm{~mm}$ lateral to the midline, was made for access to VPm, while one centered 2-4 mm caudal to bregma and 5-7 mm lateral to the midline was made for accessing barrel cortex. A small slit was made in the dura over the cortical window to allow insertion of recording micropipettes (below). A steel post was fixed to the skull with dental acrylic for holding the animal's head without pressure points and for allowing unrestricted access to the left face. A dam around the craniotomy was constructed with dental acrylic, and saline was applied to the craniotomy to prevent drying of the brain surface. Following all surgical procedures, rats were moved to a vibration isolation table, and body temperature was maintained at $37^{\circ} \mathrm{C}$ with a servo-controlled heating blanket. Isoflurane anesthesia was terminated, and the rats were sedated by an intravenous infusion of fentanyl $(10 \mu \mathrm{g} / \mathrm{kg} / \mathrm{h})$. To eliminate spontaneous whisker movements, animals were paralyzed with pancuronium bromide $(1.5 \mathrm{mg} / \mathrm{kg} / \mathrm{h})$ and artificially respired ( 90 breaths $/ \mathrm{min}$ ) for the duration of the experiment. A customwritten computer program monitored the animals' blood pressure, heart rate, electrocorticograms, and tracheal air-way pressure throughout the experiment. At the end of the experiment, the animal was killed with pentobarbital ( $60 \mathrm{mg} / \mathrm{kg}$, i.v.), and transcardially perfused. The brain was excised for histological analysis of the recording sites.

Single unit recordings and antidromic identification of CT neurons. Most CT neurons that project to VPm do so in a topographic manner (Land et al., 1995). Therefore, to maximize the likelihood of finding CT neurons using antidromic stimulation, thalamic stimulating and cortical recording microelectrodes were topographically aligned by first using low impedance tungsten microelectrodes $(0.5-1.0 \mathrm{M} \Omega$ at $1000 \mathrm{~Hz}$; Frederick Haer) to map VPm and barrel cortex. A low impedance stimulating electrode $(<0.5 \mathrm{M} \Omega$ at $1000 \mathrm{~Hz}$; Frederick Haer) was then placed in the thalamic barreloid which corresponded physiologically to the cortical barrel-related column.

CT neurons were recorded extracellularly with patch-type glass pipettes in a juxtasomal configuration; this allowed injection of depolarizing current to facilitate activity of otherwise silent or weakly firing CT cells (below). Microelectrodes were filled with a solution containing; 100 mu K-gluconate, 11 mm EGTA, $10 \mathrm{~mm} \mathrm{KCl,} 1 \mathrm{~mm} \mathrm{MgCl}_{2}, 1 \mathrm{~mm} \mathrm{CaCl}_{2} \times$ $2 \mathrm{H}_{2} \mathrm{O}, 10 \mathrm{~mm}$ HEPES, $0.017 \mathrm{~g}$ of GTP, and $0.11 \mathrm{~g}$ of ATP; in some cases $3 \%$ biocytin was included. The solution was $\mathrm{pH}$ balanced to 7.2 with an osmolarity of $280 \mathrm{mOsm}$. The microelectrodes were visualized using $100 \times$ dry objective. Tip diameters were $\sim 1 \mu \mathrm{m}$, and impedances ranged from 13 to $18 \mathrm{M} \Omega$. The glass micropipettes were advanced perpendicular to the cortical surface using a hydraulic microdrive.

Antidromic stimulation consisted of $1.4 \mathrm{~ms}$ biphasic $(0.7 \mathrm{~ms}$ initial phase and $0.7 \mathrm{~ms}$ later phase), constant-voltage pulses (5-7 V) delivered at intervals of $1.5 \mathrm{~s}$. The polarity of the current pulses was changed periodically (initially negative to initially positive and vice versa) to maximize identification of CT cells. The cortical electrode was advanced slowly during thalamic stimulation to detect antidromic spikes. Antidromic identification of CT cells was based on criteria previously described by (Swadlow, 1998; Kelly et al., 2001). A neuron was accepted as antidromically activated if it met the following criteria: (1) the presence of a discrete threshold, (2) an invariable antidromic latency $( \pm 0.1 \mathrm{~ms})$ in the absence of a preceding spontaneous spike (see below), and (3) a refractory period $<2 \mathrm{~ms}$. To avoid erroneous classification of layer $\mathrm{V}$ corticofugal neurons whose axons of passage may have been activated by current spread from the stimulating electrode, we selected only antidromically activated neurons that displayed supernormality, defined as an increase in conduction velocity in response to the second of two pulses at interpulse intervals of 7-12 ms. We measured supernormality as the percentage decrease in antidromic latency to the second of the two pulses. Supernormality is characteristic of CT neurons that project to VPm. Layer V corticofugal neurons, including those that project to the posterior nucleus of the thalamus (POm), do not display conduction supernormality (Swadlow, 1989, 1990; Kelly et al., 2001). Because spontaneous firing rates of most layer 6 CT cells is low, spontaneous activity does not confound the supernormality assessment. Layer 5 cells possess higher spontaneous firing. If an antidromically identified cell fired spontaneously, we examined spike latency jitter only when the antidromic spike was not preceded by a spontaneous spike, accomplished using a digital oscilloscope with a pretrigger delay. For a small number of cells where spontaneous activity was present, a collision test was performed to confirm further the antidromic nature of the response.

After Kelly et al. (2001), we estimate the distance between stimulation sites in VPm and layer 6 of barrel cortex to be $5.0 \mathrm{~mm}$. Conduction velocity in $\mathrm{m} / \mathrm{s}$ was calculated as the antidromic latency divided by the distance. We did not attempt to account for the amount of time, estimated by others to be $\sim 0.2 \mathrm{~ms}$ (Swadlow, 1990), required for the electrical stimulus to evoke an antidromic spike; thus, conduction velocities may be somewhat underestimated.

With juxtasomal recording, spiking activity can be evoked in a neuron using depolarizing (positive-going) current pulses. We established a stable juxtasomal configuration by slowly advancing the microelectrode while injecting, through an Axoprobe 1A amplifier (Axon Instruments), $500 \mathrm{~ms}$ current pulses of $\sim 0.5 \mathrm{nA}$. Once a CT cell was encountered, pulse intensity was gradually incremented, up to $3.0 \mathrm{nA}$ as needed, to establish a good seal. The current pulses seemed to draw the cell closer to the micropipette tip, forming a loose seal (Pinault, 1996). When a current intensity was reached at which the cell spiked consistently, current intensity was reduced to a level sufficient to evoke 1 or 2 spikes for each current pulse. Spike amplitudes were typically $5-10 \mathrm{mV}$. A cell thus entrained was recorded in this manner for $10 \mathrm{~min}$ before initiating whisker deflection protocols to ensure that the recordings were stable. In some cases we used this period to inject biocytin into the cell for subsequent histological identification.

Stimulus protocols. Hand-held probes were used to identify a cell's PW, defined as the whisker evoking the most robust response. Because many CT cells were unresponsive, the PW was determined by observing responses of other neurons in the vicinity encountered before establishing a patch on a CT neuron. When a CT neuron was found, the PW was attached to a computer-controlled piezoelectric stimulator that deflects the whisker in different directions (Simons, 1983). We positioned the stimulator on the whisker $10 \mathrm{~mm}$ from the skin surface. Ramp-and-hold deflections of $1 \mathrm{~mm}$ amplitude and having onset and offset velocities of $\sim 125 \mathrm{~mm} / \mathrm{s}$ and an intervening plateau duration of $200 \mathrm{~ms}$ were applied at interstimulus intervals of $1.5 \mathrm{~s}$. Individual whiskers were deflected in 8 directions (in $45^{\circ}$ increments relative to the horizontal alignment of the whisker row). The 8-direction stimuli were delivered in pseudorandom manner.

Juxtasomal current pulses were used to probe subthreshold responses of CT neurons. Current intensity was set such that the cell fired $1-3$ spikes for each 500 ms current pulse. For cells with inhibitory receptive fields (RFs), current intensity was increased so that the cells fired 3-5 spikes for each $500 \mathrm{~ms}$ current pulse; the higher firing rates are needed to detect stimulus-evoked decreases in firing. The mean firing rate of cells having excitatory RFs thus injected was $4.8 \pm 5.3 \mathrm{~Hz}$ and that of cells having inhibitory RFs was $10.3 \pm 9.1 \mathrm{~Hz}$. Such current pulses were delivered concurrently with the 200-ms-long whisker deflections, which were centered in time with respect to the current pulse (see Fig. 2 for illustration).

The experimental protocol consisted of three conditions: (1) whisker deflection alone, (2) whisker deflection during concurrent juxtasomal current injection (hereafter denoted the "test" condition), and (3) current injection alone. A stimulus block consisted of 16 pseudorandomly ordered PW deflections of 8 directions with and without concurrent current injection. At the end of a block, 3 current pulses were delivered alone so that we could adjust current intensity, as needed, to ensure that the current pulses themselves evoked the requisite number of spikes per 500 ms pulse. A block thus consisted of 19 stimulation conditions, and 10 such blocks were used to study a CT cell.

For some cells we additionally deflected an adjacent whisker (AW), the one caudal to the PW. In these cases each stimulation block included 16 additional presentations of 8 directions of AW deflection alone and 8 
directions of AW deflection plus current injection. AW stimulation was incorporated into the block in a pseudorandom order.

Data analysis. Spike times were accumulated into peristimulus time histograms (PSTHs) having $1.0 \mathrm{~ms}$ bins. Firing rates were quantified by taking spike counts within $25 \mathrm{~ms}$ time windows (see Results) corresponding to responses evoked by deflection onset (ON response) and offset (OFF response). Statistical analyses were performed in Microsoft Excel and Analyze-it, an Excel add-on, and in SPSS. Multiple group statistical comparisons were done with the Kruskal-Wallis test and between-group comparisons were assessed with the nonparametric Mann-Whitney $U$ test.

For cells having an excitatory RF, the onset of a stimulus-evoked response was defined as the first PSTH $1 \mathrm{~ms}$ bin, within the measurement window, in which the spike count exceeded prestimulus activity levels computed in the $100 \mathrm{~ms}$ preceding stimulus onset. The prestimulus spike activity of the cell was considered to be a Poisson process, and a bin was deemed significant if the spike count exceeded the $95 \%$ confidence limit. Response duration was calculated as the time from response onset to the last statistically significant bin within the time measurement window.

Inhibitory responses were identified by the absence of firing within the measurement window. Because background spiking rates were low even with the juxtasomal facilitation, we defined the onset of a response as the first of four consecutive $1 \mathrm{~ms}$ bins having spike counts statistically smaller than prestimulus rates.

The angular tuning properties of the cells were characterized by constructing polar plots from responses to stimulus onsets in the 8 different stimulus directions. For excitatory RFs, polar plots were constructed from the mean $\mathrm{ON}$ response magnitude to deflection in the different directions plotted radially. To quantify responses of cells having inhibitory RFs, the mean response to each deflection direction was normalized as follows: (prestimulus activity - evoked activity)/(prestimulus activity + evoked activity). The prestimulus activity was calculated over a $100 \mathrm{~ms}$ period and divided by 4 to yield a prestimulus firing rate comparable to the 25 ms measurement window. A value of 1.0 thus represented complete response suppression in that direction.

We constructed population polar plots and quantified their shapes using a vector analysis. The response for each angle was converted to a vector of polar coordinates where, $x=R_{\theta} \cos _{\theta}$ and $y=R_{\theta} \sin _{\theta}$. Vectors from the 8 angles were then summed and the magnitude of the vector computed as: $\mathrm{VM}=\left(x^{2}+y^{2}\right)^{1 / 2}$. Vector (or phase) angle, which can vary over $360^{\circ}$, reflects the preferred direction of movement. When firing rates are first normalized to the maximally effective angle, vector magnitude reflects the degree of tuning (see Khatri and Simons, 2007), such that large values indicate better tuning.

\section{Results}

We recorded from 75 antidromically identified VPm-projecting CT neurons, hereafter denoted as CT cells. All of the cells were located near the layer V/VI border or within layer VI itself, as indicated by microdrive readings and examination of biocytinlabeled cells, where available. Labeled cells were pyramidal in nature with apical dendrites extending into overlying layer IV; analyses of neuronal morphology will be presented at a later date.

The antidromic latencies of CT neurons ranged from $0.72 \mathrm{~ms}$ to $5.44 \mathrm{~ms}$ with a mean of $2.12 \pm 0.96 \mathrm{~ms}$ (Fig. $1 \mathrm{~A}$, Table 1 ). Mean conduction velocity $(2.84 \pm 1.20 \mathrm{~m} / \mathrm{s})$ was comparable to that previously reported for layer VI CT neurons in the rat somatosensory cortex (Kelly et al., 2001) (see also Swadlow and Hicks, 1996). CT neurons within deep layer VI tend to have slower conduction velocities (Fig. $1 \mathrm{~B}$ ), although we found no significant effect of recording depth (Swadlow and Weyand, 1987; Kelly et al., 2001). Similarly, conduction velocity and supernormality were unrelated (see also Swadlow, 1991). Seventeen of 75 CT neurons $(22.6 \%)$ were spontaneously active with a mean firing rate of $2.15 \pm 2.53 \mathrm{~Hz}$. Cells were considered spontaneously active if they fired one or more spikes before stimulus presentation during the 80 trials. Cells that did not fire spikes during the period
A

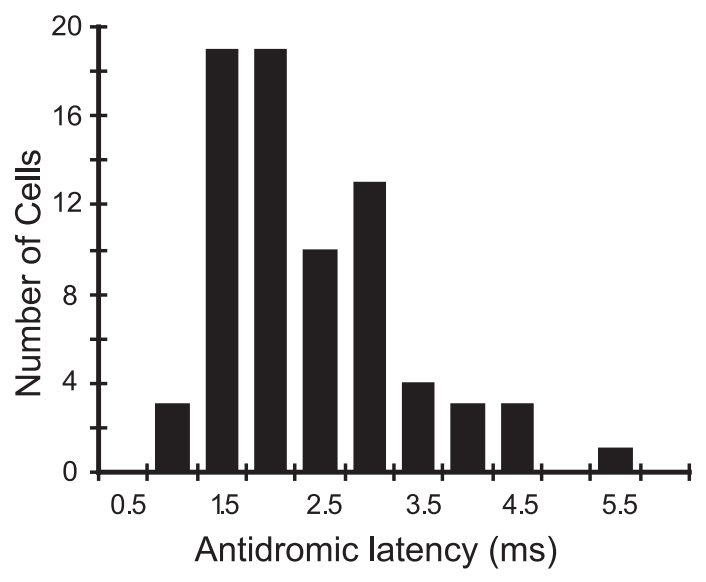

B

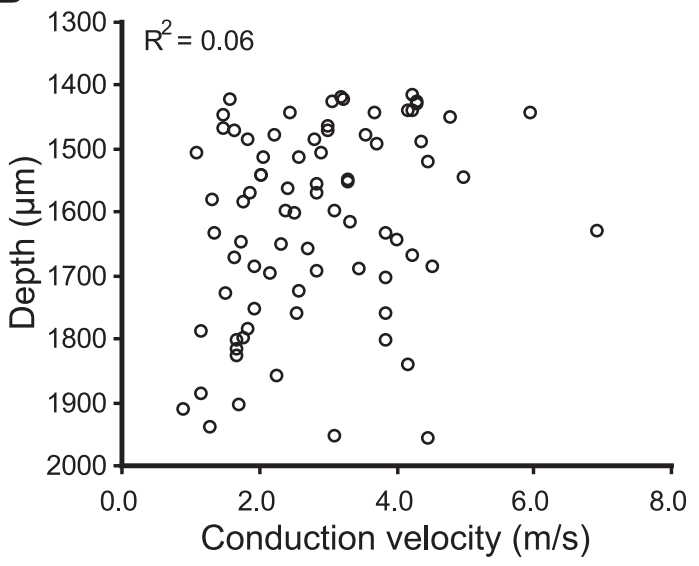

Figure 1. Axon conduction properties. $\boldsymbol{A}$, Distribution histogram of antidromic latencies of 75 CT neurons. $\boldsymbol{B}$, Relationship between conduction velocity and recording depth.

of quantitative analysis were observed qualitatively to lack spontaneous firing throughout the study of the cell. Under control conditions (no juxtasomal current pulses), only 19 cells displayed whisker (PW)-evoked activity, 15 being excited by whisker deflection and 4 being inhibited (see Fig. 2C). Of these 19 cells, 11 were spontaneously active. For cells having excitatory RFs whisker-evoked response latencies ranged from 6.0 to $39.0 \mathrm{~ms}$ (mean: $18.2 \pm 11.6 \mathrm{~ms}$, Table 1 ). Average response magnitude of the cells that responded to whisker deflection was $0.24 \pm 0.33$ spikes/stimulus, calculated over all 8 deflection angles, and the mean response to the maximally activating angle was $0.88 \pm 1.40$ spikes/stimulus. Inhibited cells had response latencies ranging from 6 to $10 \mathrm{~ms}$ (mean: $8.25 \pm 1.71 \mathrm{~ms}$ ).

Fifty-six of 75 tested cells did not respond to manual or controlled whisker deflections. Fifty of these nonresponsive cells did not fire spontaneously, either. Thus, in the control condition, $66.7 \%$ of the CT cells were completely silent, displaying neither spontaneous nor whisker-evoked firing. Twenty-seven of these silent CT cells were successfully tested for subthreshold response properties using concurrent juxtasomally applied current injections; with juxtasomal pulses 21 of them displayed a whiskerevoked response. These cells had a mean conduction velocity of $2.82 \pm 0.95 \mathrm{~m} / \mathrm{s}$. The remaining 6 initially silent cells failed to respond to either PW or AW deflections even though the juxtasomal current pulses alone were effective at evoking spikes; there 
Table 1. Summary of CT cell properties

\begin{tabular}{|c|c|c|c|c|c|c|}
\hline & \multicolumn{2}{|l|}{ Excited cells } & \multicolumn{2}{|l|}{ Inhibited cells } & \multicolumn{2}{|c|}{ Nonresponsive cells $^{a}$} \\
\hline & $\begin{array}{l}\text { Suprathreshold } \\
(n=15 \text { of } 75)\end{array}$ & $\begin{array}{l}\text { Subthreshold } \\
(n=10 \text { of } 36)\end{array}$ & $\begin{array}{l}\text { Suprathreshold } \\
(n=4 \text { of } 75)\end{array}$ & $\begin{array}{l}\text { Subthreshold } \\
(n=15 \text { of } 36)\end{array}$ & $\begin{array}{l}\text { Control } \\
(n=56 \text { of } 75)\end{array}$ & $\begin{array}{l}\text { Depolarized } \\
(n=6 \text { of } 36)\end{array}$ \\
\hline Conduction velocity (m/s) & $3.33 \pm 1.23$ & $2.69 \pm 0.89$ & $2.85 \pm 0.36$ & $2.41 \pm 1.08$ & $2.73 \pm 1.23$ & $2.76 \pm 1.50$ \\
\hline Supernormal period (\%) & $8.8 \pm 4.3$ & $9.2 \pm 4.9$ & $7.1 \pm 2.5$ & $8.9 \pm 3.9$ & $11.3 \pm 6.0$ & $10.95 \pm 7.29$ \\
\hline Refractory period (ms) & $1.11 \pm 0.36$ & $1.05 \pm 0.31$ & $1.04 \pm 0.34$ & $0.94 \pm 0.23$ & $1.08 \pm 0.33$ & $1.17 \pm 0.19$ \\
\hline Whisker-evoked latency (ms) & $18.2 \pm 11.6$ & $12.2 \pm 8.6$ & $8.3 \pm 1.7$ & $6.9 \pm 1.4$ & & \\
\hline Mean $\mathrm{ON}^{d}$ & $0.24 \pm 0.33$ & $0.71 \pm 0.62$ & & & & \\
\hline Max ON & $0.88 \pm 1.40$ & $1.42 \pm 1.33$ & & & & \\
\hline Mean OFF & $0.14 \pm 0.26$ & $0.69 \pm 0.65$ & & & & \\
\hline Max OFF & $0.43 \pm 0.64$ & $1.49 \pm 1.40$ & & & & \\
\hline
\end{tabular}

${ }^{a}$ Cells without whisker-evoked responses in the control condition.

${ }^{b}$ Cells with whisker-evoked responses in control condition.

'Cells that displayed whisker-evoked responses only with applied depolarizing current.

${ }^{d}$ Response magnitude to stimulus onsets (ON) and offsets (OFF) in spikes/stimulus.

was no depth bias in the location of these neurons (Fig. 3). These cells had a mean conduction velocity of $2.76 \pm 1.5 \mathrm{~m} / \mathrm{s}$.

\section{Neurons having excitatory responses}

Figure $2 \mathrm{~A}$ shows PSTHs of a silent CT cell that displayed a subthreshold excitatory response to PW deflections. Under control conditions (left) this cell fired no spikes during 80 trials of $500 \mathrm{~ms}$ each. With concurrent juxtasomal current injection (right), the cell fired robustly to PW deflections with a mean response magnitude of $1.83 \pm 0.82 \mathrm{spikes} /$ stimulus at the maximally effective angle $\left(225^{\circ}\right.$, see face drawing). The polar plot in Figure $2 \mathrm{~A}$ (right) illustrates the general finding that under conditions of juxtasomally applied current, nearly all responsive CT cells displayed angular tuning, indicated by oriented polar plots. As noted above, $20 \%$ ( 15 of 75 ) of the cells were excited by whisker deflection in the control condition (suprathreshold excited cells in Table 1); this proportion increased to $36 \%$ ( 13 of 36 ) with facilitation by juxtasomal current pulses (Fig. 2C). Most CT cells showing whisker-evoked firing in the control condition were located near the layer V/VI border and in superficial layer VI (Fig. 3A). With juxtasomal facilitation, responsive cells were distributed somewhat more homogenously from superficial to deep layer VI (Fig. $3 B)$.

With juxtasomal current pulses, PW deflections evoked excitatory $\mathrm{ON}$ responses or, at some angles, no response; whisker deflections did not suppress ON responses in any of these 13 neurons. Three of these cells exhibited suprathreshold responses before facilitation with juxtasomal current pulses (suprathreshold excitatory cells in Table 1), whereas the remaining 10 displayed neither spontaneous nor whisker-evoked activity in the control condition. The three cells displaying suprathreshold responses in the control condition had somewhat faster conduction velocities than 10 cells that were silent in the control condition $(3.93 \pm 0.73$ Vs $2.69 \pm 0.89 \mathrm{~m} / \mathrm{s}$; Mann-Whitney $U ; p=0.049)$. For all cells excited by whisker deflection, either in control or depolarized conditions, conduction velocities was on average somewhat faster for cells with suprathreshold responses. This difference was, however, not statistically significant (MannWhitney $U ; p=0.14$, see also Table 1 ). With juxtasomal current facilitation, response latencies of the 3 suprathreshold cells decreased by $14.3,17.1$, and $53.8 \%$.

\section{Neurons having inhibitory responses}

Figure $2 B$ illustrates the response profile of a CT neuron that was inhibited by whisker deflection. In the control condition, this example CT neuron fired only 2 spikes during the 80 trials. Jux- tasomally applied current pulses caused an increase in baseline firing which was suppressed by whisker deflection (Fig. $2 B$, right). Firing rate suppression is triggered by the transient phases of the ramp-and-hold deflection corresponding to stimulus onsets and offsets. As indicated by the polar plot, complete suppression occurred for stimulus onsets at all but one direction $\left(270^{\circ}\right)$. At the minimally inhibited angle, the response, though reduced relative to prestimulus firing, was statistically larger than at each of the other 7 angles, where firing was completely suppressed (one-tailed $t$ test; $p<0.001$ ).

Only $5 \%$ of the 75 cells tested under control conditions displayed a detectable inhibitory response, probably because the spontaneous firing levels were so low. With juxtasomal activation, $47 \%$ (17 of 36) of CT cells were inhibited by whisker deflection (Fig. 2C). Although 7 of the CT neurons with inhibitory RFs were spontaneously active before juxtasomal facilitation, due to very low firing rates only two of them could confidently be classified as inhibited in the control condition. These two cells had a mean conduction velocity of $2.98 \pm 0.37 \mathrm{~m} / \mathrm{s}$ while that of the remaining cells was $2.41 \pm 1.08 \mathrm{~m} / \mathrm{s}$. Similar to excited cells, under control conditions inhibited cells were located near the layer V/VI border and in superficial layer VI (Fig. $3 A$ ). With juxtasomal facilitation, responsive cells were more evenly distributed through the depths of layer VI (Fig. 3, compare $A, B$ ). All inhibited cells displayed only suppressed responses to both the onset and offset of PW deflection; there were no cases for which some angles evoked an excitatory response.

\section{Response magnitudes}

We quantified the magnitudes of $\mathrm{ON}$ and OFF responses in control and depolarized conditions. Response magnitudes were computed for $25 \mathrm{~ms}$ epochs beginning at response onset (or offset), identified quantitatively (see Materials and Methods); the 25 ms epoch captures the large, transient component of the responses (e.g., Fig. 4A). In the depolarized condition, mean $\mathrm{ON}$ response magnitude was $1.73 \pm 1.54$ spikes/stimulus for the best, or maximally effective, deflection angle, and the mean response averaged over all angles was $0.72 \pm 0.55$ spikes/stimulus. The mean OFF response for the best angle was $1.52 \pm 1.22$ spikes/ stimulus, and the mean response over all 8 angles was $0.70 \pm 0.57$ spikes/stimulus. These values are within the range of firing rates normally observed in barrel cortex (Armstrong-James and Fox, 1987; Simons and Carvell, 1989; Armstrong-James et al., 1991). The mean OFF/ON ratio, $0.79 \pm 0.50$, is similar to that reported for thalamic neurons but greater than that of layer IV regular spike units (see Discussion). 
A

0

\begin{tabular}{l}
\hline 45 \\
\hline 90 \\
\hline 135 \\
\hline 180 \\
\hline 225 \\
\hline 270 \\
\hline 315 \\
\hline All \\
\hline
\end{tabular}

18
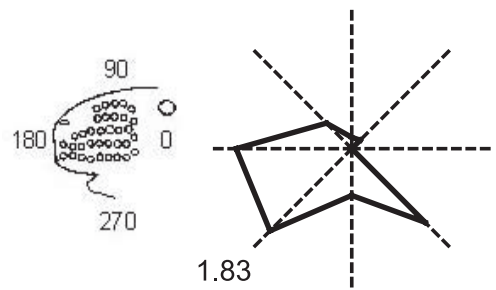

B

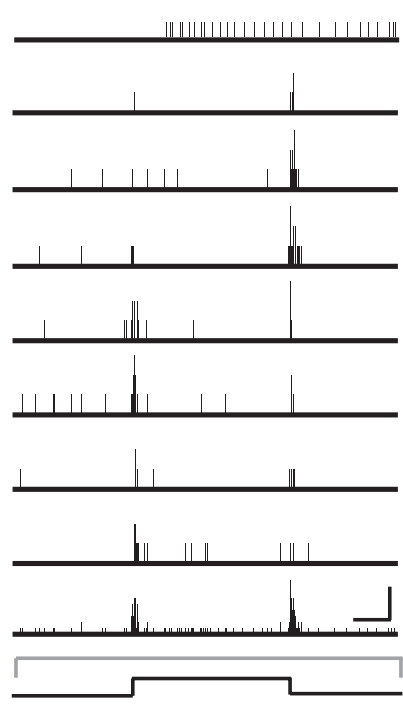

0
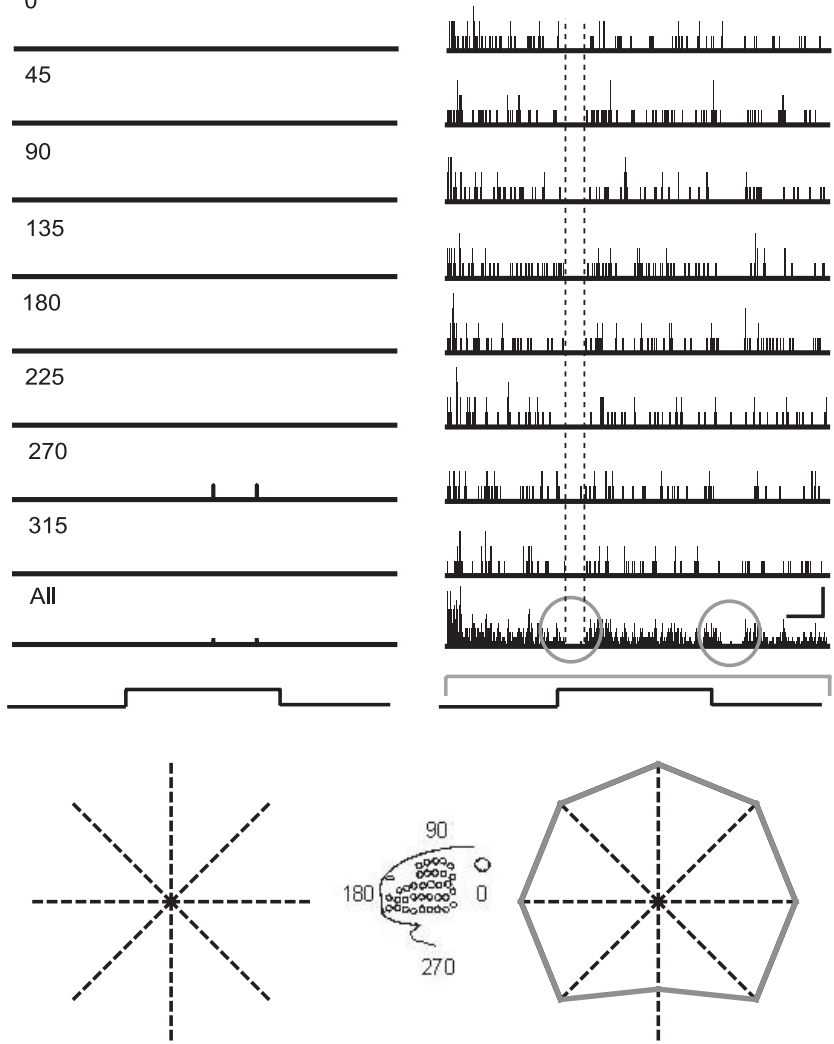

D

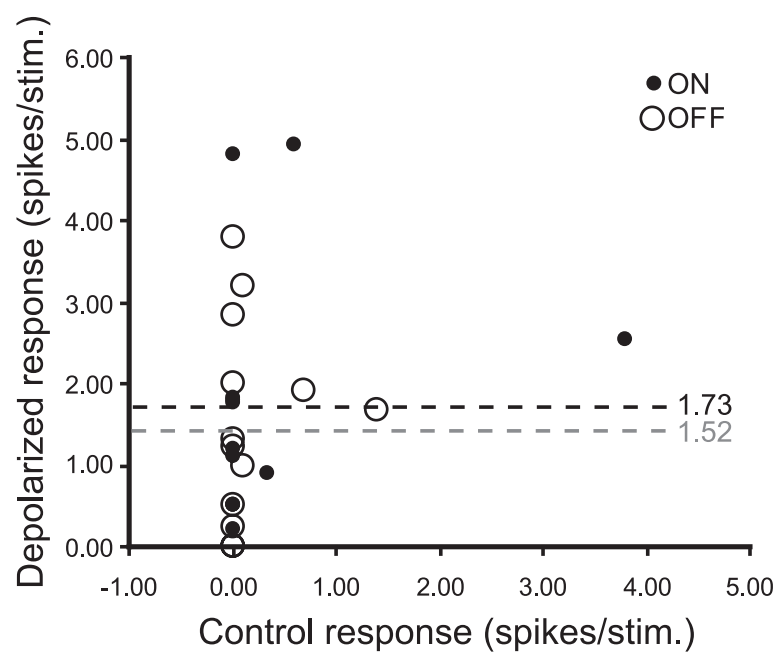

Figure 2. Excited and inhibited CT neurons. A, PSTHs of whisker-evoked responses of a representative CT neuron having an excitatory receptive field. Left, Control condition, whisker deflection without juxtasomal current injection. Right, Test condition, whisker deflection concurrent with juxtasomal current pulse. PSTHs having $1 \mathrm{~ms}$ bins were constructed from responses to 10 deflections in each of the 8 directions indicated (see sketch for orientation). The bottom-most PSTH is the response accumulated over all stimuli/angles. The duration of each trial was $500 \mathrm{~ms}$ with the ramp-and-hold stimulus centered in time (indicated at the bottom). Whisker deflection is represented by black ramp-and-hold schematic while current injection is represented by the gray line. Calibration: horizontal $=50 \mathrm{~ms}$; vertical $=2$ spikes for the individual-angle PSTHs, 8 spikes for All-angle PSTH. Below each set of PSTHs is a polar plot constructed from responses evoked by stimulus onset; the maximal angle response is indicated in spikes/stimulus. All of the spikes in the $0^{\circ}$ PSTH, with juxtasomal depolarization, occurred as train of spikes during one trial only. $\boldsymbol{B}$, PSTHs of a representative CT neuron having an inhibitory receptive field. Conventions are as in $A$ above. Calibration: horizontal $=50 \mathrm{~ms}$; vertical $=2$ spikes for the individual-angle PSTHs, 6 spikes for All-angle PSTH. Gray circles on the All-angle PSTH highlights the period of response suppression. For polar plot, maximum distance from origin indicates complete response suppression; this cell's firing was suppressed at all but one angle, $270^{\circ}$. Dotted lines on PSTHs denote the measured response epoch; spikes counts during this period were subtracted from prestimulus activity. $C$, Percentage of cells having excitatory and inhibitory receptive fields observed under control and test conditions. $D$, Excitatory response magnitudes to stimulus onsets ( $0 \mathrm{~N}$ ) and offsets ( $\mathrm{OFF}$ ) under control condition and when cells are juxtasomally injected with depolarizing current pulses. 
A

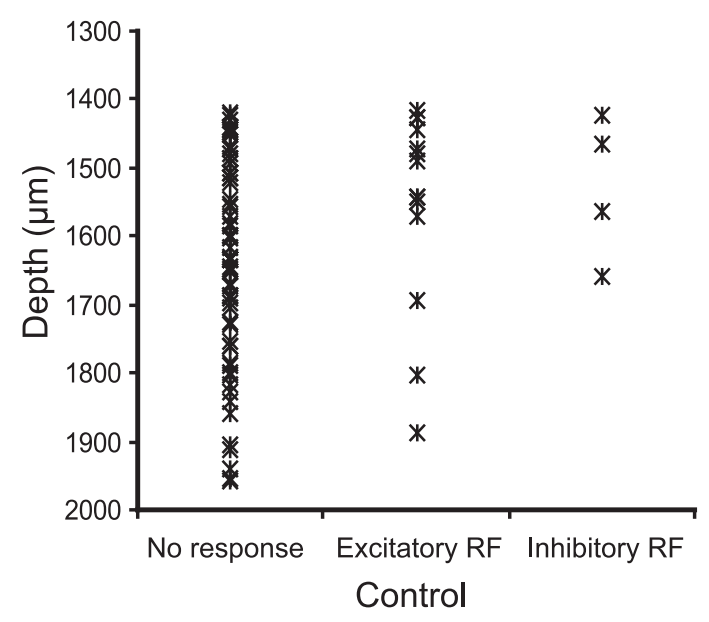

B

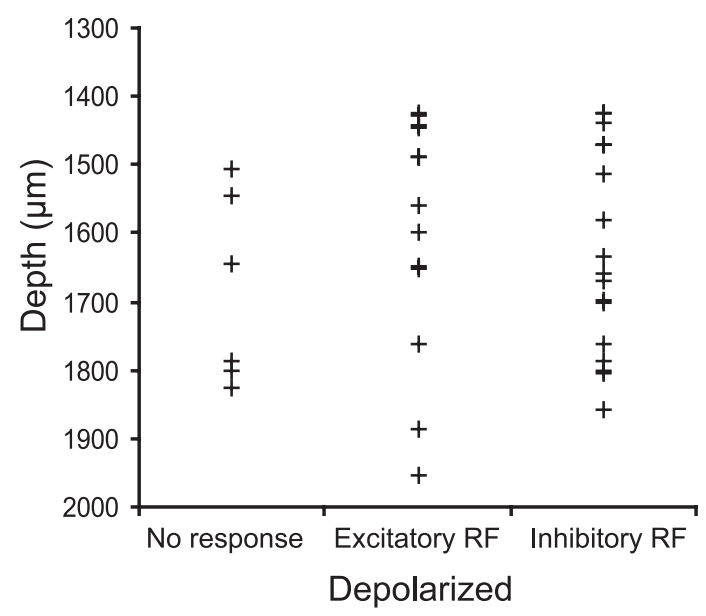

Figure 3. Depth distribution of neurons showing excitatory and inhibitory responses or no response to whisker deflections in control $(\boldsymbol{A})$ and juxtasomally depolarized $(\boldsymbol{B})$ conditions.

\section{Time course of inhibited and excited responses}

We constructed population PSTHs from all cells that responded to whisker deflections during juxtasomal current injection; PSTHS were constructed separately for CT cells having excitatory (Fig. 4A) or inhibitory (Fig. $4 B$ ) responses. The following analyses are based on these responses. The population PSTH of excited neurons has a robust short-latency peak followed by a period of more prolonged and lower activity. Examination of individual neuron PSTHs suggested two types of responses profiles: (1) robust responses having rapid rise times and short durations, and (2) weak responses having slower rise times and longer durations. To quantify these differences, we used a moving box-car method ( 3 ms bins) to smooth each individual PSTH and then calculated the time to the peak response relative to response onset. This measure of rise time was plotted as a function of the latency of the peak response relative to stimulus onset (Fig. $4 C$, inset). These measures of response rise time and latency to peak are highly correlated $\left(R^{2}=0.81\right)$, and the distribution of the conjoint values is bimodal. Most cells $(n=9)$ display early, rapid rising responses, whereas the firing of the remaining 4 cells takes longer to reach peak values and is more temporally dispersed during the response. The early, transient component of the response of the former group ended at nearly the same time that the response of the latter group began (Fig. 4D). We denote these two different response profiles as characterizing a short-latency excitatory group and a long-latency excitatory group. For the inhibited group, suppression of firing corresponds temporally to the period during which short-latency excited cells fire most robustly (Fig. 4, compare $B, D$ ).

When considered as a single group, excited neurons respond at a longer mean latency than inhibited neurons (Fig. 4E) $(13.03 \pm 9.04 \mathrm{~ms}$ vs $6.88 \pm 1.62 \mathrm{~ms}$, respectively; Mann-Whitney $U ; p=0.02$ ). Response onsets of the short-latency excitatory group are, however, comparable to those of inhibited cells $(8.71 \pm 3.68$ vs $6.88 \pm 1.62 \mathrm{~ms}$, respectively; $p=0.26)$. Longlatency excitatory neurons have an average response onset $(22.75 \pm 10.44 \mathrm{~ms})$ greater than that of both the short-latency excitatory group and the inhibited group (Fig. $4 E)(p=0.01$ and $p<0.001$, respectively).

Antidromic latencies of the short-latency excitatory group (antidromic latency: $1.63 \pm 0.38 \mathrm{~ms}$ ) were shorter than those of inhibited neurons $(2.34 \pm 0.88 \mathrm{~ms}, F$ test followed by MannWhitney $U ; p=0.047$ ) (Fig. $4 F$ ) but similar to those of longlatency excited cells (Mann-Whitney $U ; p=0.68$ ). The inhibited and long-latency excitatory groups did not differ (Mann-Whitney $U ; p=0.65$ ). There were no significant differences among the three groups for supernormality or absolute refractory period (Kruskal-Wallis; $p$ values $>0.10$ ).

\section{Angular tuning}

CT neurons, like other vibrissa-responsive cells, display preferences for the direction of whisker deflection (e.g., Fig. $2 A, B$ ). For each individual cell, we normalized its polar plot to the spike count at the maximally effective angle and then averaged across cells to obtain a population polar plot. The shape of the population polar plot thus reflects the overall tuning of the cells without regard to actual firing rates, and this is represented by the direction and magnitude of the vectors. The short-latency group fired most robustly to down-and-forward deflections and the longlatency group fired best to up-and-forward deflections. The length of the vector for the long-latency group was larger suggesting somewhat greater tuning, or angular selectivity, among these cells $(1.25 \pm 0.60$ vs $1.05 \pm 0.0 .60)$. The firing of cells having inhibited responses is more suppressed when the whisker is moved in a rostral-dorsal direction; the mean tuning vector $(0.70 \pm 0.65)$ was slightly shorter than that of the short-latency and long-latency excited groups. Differences in vector magnitudes among the groups were not, however, statistically significant (Kruskal-Wallis; $p=0.16$ ).

\section{Adjacent whisker responses}

For 17 cells we additionally examined responses to deflections of the caudally adjacent whisker. The scatter-plot of Figure 5 shows corresponding PW and AW responses observed during juxtasomal depolarization. Response magnitude was computed, in each case, as the average response to all 8 directions of whisker deflection and normalized for prestimulus firing rates (i.e., prestimulus activity was subtracted from evoked activity). Cells having inhibited responses are represented by negative firing rates. With PW deflections, 6 cells displayed excitatory responses while 10 cells had inhibited responses; 1 cell did not respond to either PW or AW deflection. Nine of the cells inhibited by PW deflection were also inhibited by AW deflection. Cells excited by PW deflection were more varied; 3 cells failed to respond to AW deflection, 1 was inhibited by AW deflection and the other 2 were excited, albeit with lower response magnitudes relative to the cell's PW-evoked 
response. Our sample is too small to assess whether differences among excited cells is related to response latency.

\section{Discussion}

We examined response properties of CTVPm-projecting cells using antidromic stimulation and juxtasomal recording techniques. Similar to findings in other sensorimotor cortices and in primary visual cortex (Tsumoto and Suda, 1980; Landry and Dykes, 1985; Swadlow, 1991; Swadlow and Hicks, 1996; Beloozerova et al., 2005; Sirota et al., 2005), most CT cells fire few, if any, spikes under control conditions. In our sample, most cells displayed little or no spontaneous firing, and $75 \%$ were unresponsive to whisker deflections. Using juxtasomally injected currents, we were able to unmask subthreshold peripheral receptive fields. In total, with juxtasomally induced depolarization, $83 \%$ of cells could be shown to have whisker-driven responses, with $36 \%$ displaying excitatory RFs and $47 \%$ inhibitory RFs. CT neurons with excitatory receptive fields can be divided into two subclasses, short-latency and long-latency excitatory response groups. Short-latency excitatory CT neurons have faster conduction velocities than CT cells having inhibitory receptive fields.

Corticothalamic neurons in layer VI have apical dendrites that extend into layer $\mathrm{V}$ and lower layer IV and basilar dendrites that extend deeper into layer VI (White and Hersch, 1982; White and Keller, 1987; Zhang and Deschênes, 1997). Thalamocortical synapses from VPm terminate on both sets of dendrites (White and Hersch, 1981). Short-latency excitatory cells may be more likely than long-latency cells to receive such direct thalamic inputs. In contrast long-latency CT cells lack a robust early response, suggesting that their sensory-evoked activity depends greatly on intracortical, polysynaptic afferent inputs. Some short-latency cells have long-duration responses; thus, they too might receive relatively abundant polysynaptic drive in addition to direct thalamocortical inputs.

We observed a large proportion of cells that exhibited shortlatency inhibited responses without a preceding excitatory response. This was unexpected because CT neurons in somatosensory, motor, and visual cortices have been described near uniformly as displaying excitatory RFs when peripherally driven responses can be evoked (Tsumoto and Suda, 1980; Landry and Dykes, 1985; Sirota et al., 2005). For example, subthreshold inhibited responses to center-RF stimulation were not observed in intracellular recordings from CT neurons in cat somatosensory cortex (Landry and Dykes, 1985) nor were they observed in visual cortex neurons projecting to the lateral geniculate nucleus (Ferster and Lindström, 1983). A small number (5 of 56) of CT neurons having inhibitory RFs have been observed, however, in so-
D

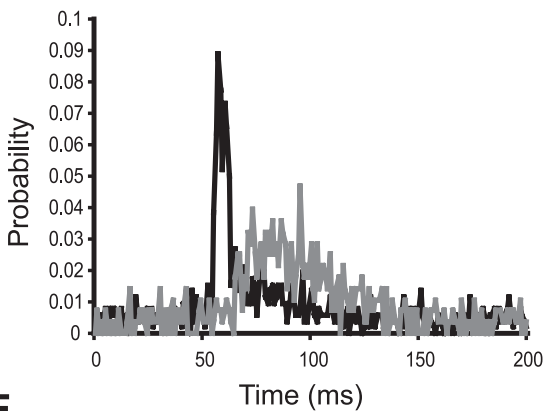

E

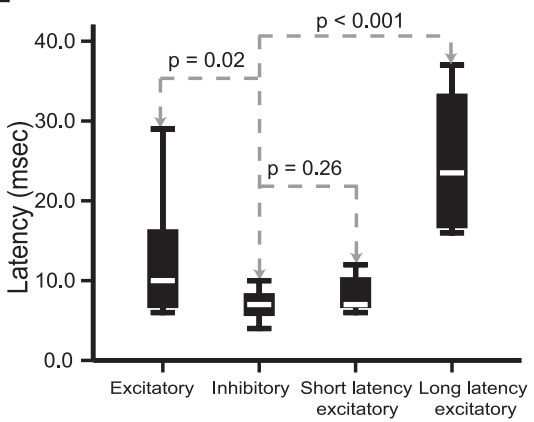

$\mathbf{F}$

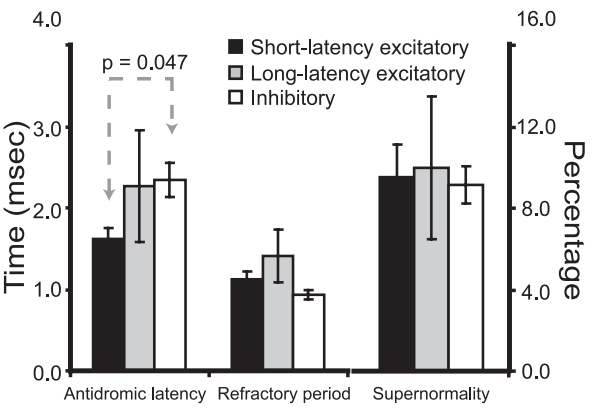

Figure 4. Functional properties of excited and inhibited (T neurons. $A, B$, Population PSTHs showing juxtasomally facilitated responses of neurons having excitatory $(\boldsymbol{A})$ and inhibitory $(\boldsymbol{B})$ RFs. Ordinate indicates the probability of a spike in each $1 \mathrm{~ms}$ bin excitatory RFs. Black circles denote short-latency excitatory group and gray circles denote long-latency excitatory group. $\boldsymbol{D}$ lation PSTHs of short-latency (black) and long-latency (gray) excitatory neurons. $E$, Response onset latencies. Median is represent data within 1.5 times the range from the first to the third quartile. $p$ values are based on Mann-Whitney Utest. $\boldsymbol{F}$, Axonal conduction properties. Supernormality values are represented on the right ordinate. Error bars represent SEM.

matosensory cortex of awake rabbits (Swadlow and Hicks, 1996). In that study, brief juxtasomal current pulses were applied at different times after a whisker deflection, and changes were noted in the threshold current needed to elicit a juxtasomally induced spike. The relatively large proportion of inhibited cells observed in our study may reflect the greater ease of identifying inhibitory responses when background activity is tonically elevated, here using DC recordings and long juxtasomal current pulses. Also, with this approach, the time course of subthreshold responses can be more readily discerned. We found that background firing ceased within a few milliseconds of whisker deflection, suggesting a fast feedforward mechanism wherein inhibited CT cells receive inputs from local inhibitory interneurons that are in turn monosynaptically contacted by TC cells (see White and Keller, 1987; Zhang and Deschênes, 1997). Under some behavioral conditions, background and/or stimulus-related firing rates of CT cells might be elevated by means of facilitating inputs from other cortical 


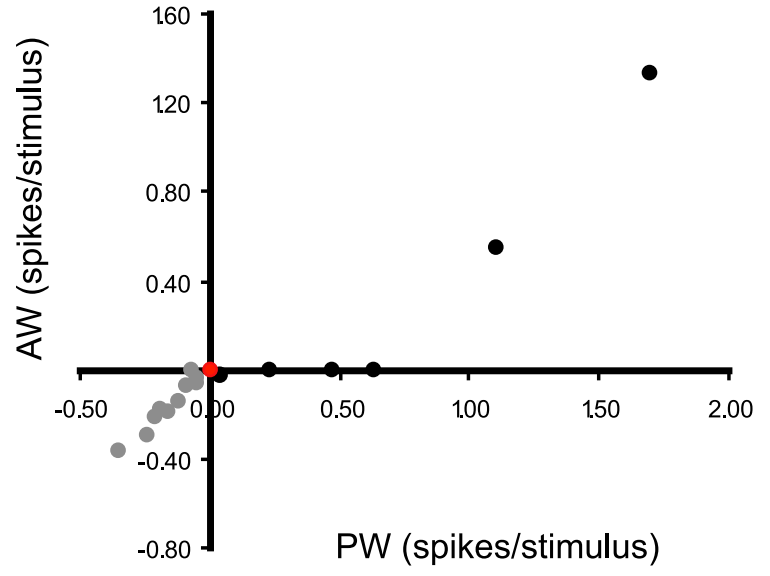

Figure 5. Principal whisker and adjacent whisker responses. Relationship between PW-and AW-evoked $0 \mathrm{~N}$ responses during juxtasomal depolarization. Negative numbers indicate that responses are suppressed below prestimulus firing rates. Black circles, Neurons that were excited by PW deflections; gray circles, neurons that were inhibited by PW deflections; red circle, unresponsive neuron.

areas (Lee et al., 2008), providing a circumstance wherein inhibited CT cells can exert a postsynaptic effect.

Anatomically, CT neurons form a synaptic triad with TC axons and local inhibitory neurons (White and Keller, 1987). CT cells and inhibitory interneurons receive direct TC input and are reciprocally connected with each other. Excitatory neurons within layer IV barrels are embedded in similar circuits. Several lines of evidence suggest, however, that CT circuitry may operate differently from the local circuit in layer IV. In barrels robust excitatory responses are followed by strong inhibition that truncates the excitatory response, even when the neuron's activity is enhanced by application of a GABA antagonist (Kyriazi et al., $1996,1998)$. In contrast, excitatory responses in many CT neurons persist, albeit at lower firing rates, for $50 \mathrm{~ms}$ or more (see Fig. $4 A, D)$. Thus, postexcitatory inhibition in CT neurons may be less robust than in layer IV neurons. Consistent with this, OFF/ON ratios differ between barrel neurons (RSUs) and juxtasomally depolarized CT neurons whose overall firing rates are nonetheless similar to those of barrel neurons. For barrel neurons, OFF responses are disproportionately smaller than those of VPm neurons, and this is thought to reflect strong, fast feedforward inhibition (Kyriazi et al., 1994; Pinto et al., 2003). OFF/ON ratios of CT neurons are more similar to those in VPm, suggesting different local circuit mechanisms. Additionally, shortlatency inhibitory-only responses are rarely evoked in layer IV neurons by PW deflections, and when they occur, they do so in septal not barrel regions (Moore and Nelson, 1998; Sachdev et al., 2000). Also, CT neurons having inhibitory RFs lacked a shortlatency excitatory component that could be ascribed to direct TC connections. Together the finding suggests that there are at least two different types of local circuits involving CT neurons.

One function of corticothalamic neurons may be selective enhancement of sensory-evoked signals in the thalamus (Tsumoto et al., 1978; Ahlsen et al., 1982; Webb et al., 2002; Temereanca and Simons, 2004; Sirota et al., 2005). In the whisker system, CT cells project to VPm in a highly topographic manner (Land et al., 1995; Alloway et al., 2003), and, as in other systems, CT synapses on VPm neurons are excitatory (Castro-Alamancos and Calcagnotto, 1999; Sherman, 2007) Functionally, when CT and VPm neurons share the same RF center (i.e., a common PW), the net effect of CT feedback is excitatory (Temereanca and Simons,
2004; Lee et al., 2008). When CT and VPm neurons are not topographically aligned, activation of CT neurons leads to suppression of VPm firing or no effect. Suppression, when observed, is thought to reflect indirect inhibition mediated by the thalamic reticular nucleus (RTn) (Temereanca and Simons, 2004). Our findings suggest an additional circuit mechanism by which VPm responses can be selectively enhanced, in this case by means of RTn-mediated disynaptic disinhibition involving inhibited CT neurons. In this hypothetical model, when the background firing of inhibited cells is suppressed by PW deflection, their excitatory drive onto RTn cells is removed, thereby relieving RT-mediated inhibition of VPm cells in the corresponding thalamic barreloid. If inhibited CT cells directly excite VPm neurons, then suppression of their firing by PW deflections would reduce VPm responses, the converse of what has been observed when activity is enhanced in the topographically aligned region of layer VI (Temereanca and Simons, 2004; Lee et al., 2008). The corticothalamic-thalamocortical system may thus function as a push-pull type circuit, with excited CT cells providing direct facilitation to VPm (Temereanca and Simons, 2004; Lee et al., 2008) and inhibited CT cells causing indirect facilitation by the removal of inhibition. One prediction of this model is that CT neurons having inhibitory receptive fields will exert a greater influence on topographically corresponding RTn cells than CT cells having excitatory receptive fields.

\section{References}

Ahlsen G, Grant K, Lindström S (1982) Monosynaptic excitation of principal cells in the lateral geniculate nucleus by corticofugal fibers. Brain Res 234:454-458.

Alloway KD, Hoffer ZS, Hoover JE (2003) Quantitative comparisons of corticothalamic topography within the ventrobasal complex and the posterior nucleus of the rodent thalamus. Brain Res 968:54-68.

Armstrong-James M, Fox K (1987) Spatiotemporal convergence and divergence in the rat SI "barrel" cortex. J Comp Neurol 263:265-281.

Armstrong-James M, Callahan CA, Friedman MA (1991) Thalamo-cortical processing of vibrissal information in the rat. I. Intracortical origins of surround but not centre-receptive fields of layer IV neurones in the rat S1 barrel field cortex. J Comp Neurol 303:193-210.

Beloozerova IN, Sirota MG, Orlovsky GN, Deliagina TG (2005) Activity of pyramidal tract neurons in the cat during postural corrections. J Neurophysiol 93:1831-1844.

Castro-Alamancos MA, Calcagnotto ME (1999) Presynaptic long-term potentiation in corticothalamic synapses. J Neurosci 19:9090-9097.

Dykes R, Lamour Y (1988) Neurons without demonstrable receptive fields outnumber neurons having receptive fields in samples from the somatosensory cortex of anesthetized or paralyzed cats and rats. Brain Res 440:133-143.

Ferster D, Lindström S (1983) An intracellular analysis of geniculo-cortical connectivity in area 17 of the cat. J Physiol 342:181-215.

Kelly MK, Carvell GE, Hartings JA, Simons DJ (2001) Axonal conduction properties of antidromically identified neurons in rat barrel cortex. Somatosens Mot Res 18:202-210.

Khatri V, Simons DJ (2007) Angularly nonspecific response suppression in rat barrel cortex. Cereb Cortex 17:599-609.

Kyriazi HT, Carvell GE, Simons DJ (1994) OFF response transformations in the whisker/barrel system. J Neurophysiol 72:392-401.

Kyriazi HT, Carvell GE, Brumberg JC, Simons DJ (1996) Quantitative effects of GABA and bicuculline methiodide on receptive field properties of neurons in real and simulated whisker barrels. J Neurophysiol 75:547-560.

Kyriazi H, Carvell GE, Brumberg JC, Simons DJ (1998) Laminar differences in bicuculline methiodide's effects on cortical neurons in the rat whisker/ barrel system. Somatosens Mot Res 15:146-156.

Land PW, Buffer SA Jr, Yaskosky JD (1995) Barreloids in adult rat thalamus: three dimensional architecture and relationship to somatosensory cortical barrels. J Comp Neurol 355:573-588.

Landry P, Dykes RW (1985) Identification of two populations of corticothalamic neurons in cat primary somatosensory cortex. Exp Brain Res 60:289-298. 
Lee S, Carvell GE, Simons DJ (2008) Motor modulation of afferent somatosensory circuits. Nat Neurosci 11:1430-1438.

Liu XB, Honda CN, Jones EG (1995) Distribution of four types of synapse on physiologically identified relay neurons in the ventral posterior thalamic nucleus of the cat. J Comp Neurol 352:69-91.

Liu XB, Jones EG (1999) Predominance of corticothalamic synaptic inputs to thalamic reticular nucleus neurons in the rat. J Comp Neurol 414:67-79.

Metherate R, Tremblay N, Dykes RW (1988) The effects of acetylcholine on response properties of cat somatosensory cortical neurons. J Neurophysiol 59:1231-1252.

Moore CI, Nelson SB (1998) Spatio-temporal subthreshold receptive fields in the vibrissa representation of rat primary somatosensory cortex. J Neurophysiol 80:2882-2892.

Pinault D (1996) A novel single-cell staining procedure performed in vivo under electrophysiological control: morpho-functional features of juxtacellularly labeled thalamic cells and other central neurons with biocytin or Neurobiotin. J Neurosci Methods 65:113-136.

Pinto DJ, Hartings JA, Brumberg JC, Simons DJ (2003) Cortical damping: analysis of thalamocortical response transformations in rodent barrel cortex. Cereb Cortex 13:33-44.

Sachdev RN, Sellien H, Ebner FF (2000) Direct inhibition evoked by whisker stimulation in somatic sensory (SI) barrel field cortex of the awake rat. J Neurophysiol 84:1497-1504.

Sherman SM (2007) The thalamus is more than just a relay. Curr Opin Neurobiol 17:417-422.

Sherman SM, Koch C (1986) The control of retinogeniculate transmission in the mammalian lateral geniculate nucleus. Exp Brain Res 63:1-20.

Simons DJ (1983) Multi-whisker stimulation and its effects on vibrissa units in rat SmI barrel cortex. Brain Res 276:178-182.

Simons DJ (1985) Temporal and spatial integration in the rat SI vibrissa cortex. J Neurophysiol 54:615-635.

Simons DJ, Carvell GE (1989) Thalamocortical response transformation in the rat vibrissa/barrel system. J Neurophysiol 61:311-330.

Sirota MG, Swadlow HA, Beloozerova IN (2005) Three channels of corticothalamic communication during locomotion. J Neurosci 25:5915-5925.

Steriade M (2001) Impact of network activities on neuronal properties in corticothalamic systems. J Neurophysiol 86:1-39.

Swadlow HA (1989) Efferent neurons and suspected interneurons in S-1 vibrissa cortex of the awake rabbit: receptive fields and axonal properties. J Neurophysiol 62:288-308.

Swadlow HA (1990) Efferent neurons and suspected interneurons in S-1 forelimb representation of the awake rabbit: receptive fields and axonal properties. J Neurophysiol 63:1477-1498.

Swadlow HA (1991) Efferent neurons and suspected interneurons in second somatosensory cortex of the awake rabbit: receptive fields and axonal properties. J Neurophysiol 66:1392-1409.
Swadlow HA (1992) Monitoring the excitability of neocortical efferent neurons to direct activation by extracellular current pulses. J Neurophysiol 68:605-619.

Swadlow HA (1994) Efferent neurons and suspected interneurons in motor cortex of the awake rabbit: axonal properties, sensory receptive fields, and subthreshold synaptic inputs. J Neurophysiol 71:437-453.

Swadlow HA (1998) Neocortical efferent neurons with very slowly conducting axons: strategies for reliable antidromic identification. J Neurosci Methods 79:131-141.

Swadlow HA, Hicks TP (1996) Somatosensory cortical efferent neurons of the awake rabbit: latencies to activation via supra- and subthreshold receptive fields. J Neurophysiol 75:1753-1759.

Swadlow HA, Weyand TG (1987) Corticogeniculate neurons, corticotectal neurons, and suspected interneurons in visual cortex of awake rabbits: receptive-field properties, axonal properties and effects of EEG arousal. J Neurophysiol 57:977-1001.

Temereanca S, Simons DJ (2004) Functional topography of corticothalamic feedback enhances thalamic spatial response tuning in the somatosensory whisker/barrel system. Neuron 41:639-651.

Tsumoto T, Suda K (1980) Three groups of cortico-geniculate neurons and their distribution in binocular and monocular segments of cat striate cortex. J Comp Neurol 193:223-236.

Tsumoto T, Creutzfeldt OD, Legéndy CR (1978) Functional organization of the corticofugal system from visual cortex to lateral geniculate nucleus in the cat. Exp Brain Res 32:345-364.

Van der Loos H (1976) Barreloids in mouse somatosensory thalamus. Neurosci Lett 2:1-6.

Webb BS, Tinsley CJ, Barraclough NE, Easton A, Parker A, Derrington AM (2002) Feedback from V1 and inhibition from beyond the classical receptive field modulates the responses of neurons in the primate lateral geniculate nucleus. Vis Neurosci 19:583-592.

White EL, Hersch SM (1981) Thalamocortical synapses of pyramidal cells which project from SmI to MsI cortex in the mouse. J Comp Neurol 198:167-181.

White EL, Hersch SM (1982) A quantitative study of thalamocortical and other synapses involving the apical dendrites of corticothalamic projection cells in mouse SmI cortex. J Neurocytol 11:137-157.

White EL, Keller A (1987) Intrinsic circuitry involving the local axon collaterals of corticothalamic projection cells in mouse SmI cortex. J Comp Neurol 262:13-26.

Woolsey TA, Van der Loos H (1970) The structural organization of layer IV in the somatosensory region (SI) of mouse cerebral cortex. Brain Res 17:205-242.

Zhang ZW, Deschênes M (1997) Intracortical axonal projections of lamina VI cells of the primary somatosensory cortex in the rat: a single-cell labeling study. J Neurosci 17:6365-6379. 